\title{
Etnomatemática nas práticas laborais da pesca: relato de experiências e memórias
}

\author{
Ethnomathematics in fishing work practices: \\ report of experiences and memories
}

\author{
Gustavo Martins ${ }^{1}$ \\ Adriano Vargas Freitas ${ }^{2}$
}

\begin{abstract}
Resumo. O presente artigo apresenta relato de experiência elaborado a partir de pesquisa qualitativa envolvendo relato de experiências e entrevistas com pescadores e redeiros da Praia de Provetá, na Ilha Grande - em Angra dos Reis, Rio de Janeiro, região que concentram grande quantidade de caiçaras deste município. A análise das memórias e experiências laborais da pesca, que são passadas de gerações a gerações de pescadores, em uma tentativa de preservar a cultura e a sobrevivência dessa comunidade, nos permitiram verificar uma grande quantidade de conhecimentos que podem ser considerados como matemáticos, imbricados nesses saberes e fazeres. Desde a preparação para a saída da embarcação do porto, a escolha do melhor lugar para lançar a rede, até o seu retorno, quando há o acerto das contas com o proprietário da embarcação e a partilha dos resultados entre a tripulação. Mas, antes mesmo da própria pesca, uma série de outros conhecimentos estão envolvidos e são aplicados nas atividades laborais desta comunidade, por exemplo, na forma de construção e remendo das redes. Como suporte teórico para a identificação e análise desses conhecimentos, utilizamos o Programa Etnomatemática, que nos permitiu verificar o aparecimento de costumes culturais que envolvem práticas de contagem e medições diversas, muitas vezes distantes dos conhecimentos ditos escolares.
\end{abstract}

Palavras-chave. Conhecimentos laborais de pescadores, memórias e experiências, programa etnomatemática.

\footnotetext{
${ }^{1}$ Instituto de Educação de Angra dos Reis, Universidade Federal Fluminense (IEAR-UFF), gustavo357m@gmail.com

${ }^{2}$ Instituto de Educação de Angra dos Reis, Universidade Federal Fluminense (IEAR-UFF), adrianovargas@id.uff.br
} 


\begin{abstract}
This article presents an experience report. It was elaborated from qualitative research involving experience reports and interviews with fishermen and netters of Provetá Beach, in Ilha Grande - in Angra dos Reis, Rio de Janeir. This region concentrates large amount of caiçaras. We present analyzes of the memories and working experiences of fishing, which are passed from generations to generations of fishermen, in an attempt to preserve the culture and survival of this community. This allowed us to verify a large amount of knowledge that can be considered as mathematical, imbricated in this knowledge and doing. From preparing to leave the vessel, choosing the best place to launch the net until its return when the owner of the vessel is settled and the results are shared among the crew. But even before fishing itself, a host of other knowledge is involved and applied to the work activities of this community, for example in the form of construction and patching of nets. As a theoretical support for the identification and analysis of this knowledge, we use the Ethnomathematics Program, which allowed us to verify the emergence of cultural customs involving diverse counting and measurement practices, often distant from the socalled school knowledge.
\end{abstract}

Keywords. Working knowledge of fishermen, memories and experiences, ethnomathematics program.

\title{
1 Considerações iniciais
}

Iniciamos destacando que o primeiro autor deste relato de experiência é morador da vila de pescadores da Praia de Provetá, foco de nosso estudo. E que, portanto, ao nos apresentar relatos de atividades laborais desta comunidade, por vezes eles se mesclam às suas próprias memórias e experiências.

Assim, de certa forma, ao mesmo tempo que relata práticas laborais da pesca que envolvem conhecimentos matemáticos, e de outras áreas, o estudo também abre espaços para a divulgação das riquezas culturais dessa comunidade incrustada na Ilha Grande Angra dos reis, Rio de Janeiro.

Consideramos que, esta primeira parte já expõem os motivos da escolha dessa comunidade, pois, conforme comentado, é a comunidade do primeiro autor e de sua família há várias gerações. Mas, é também a região que concentra a maior quantidade de caiçaras do município de Angra dos Reis.

Por meio de estudo qualitativo, como relato experiencial, buscamos responder à seguinte questão: Quais são os conhecimentos matemáticos envolvidos nas práticas laborais da pesca da comunidade caiçara da praia de Provetá, Ilha Grande? 
Dentre os objetivos, destacamos o de verificar e analisar as práticas laborais desenvolvidas pelos pescadores da praia de Provetá, envolvendo conhecimentos de matemática.

Para isso, recorremos à metodologia qualitativa que, segundo Rodrigues (2007), pode ser entendida como uma pesquisa descritiva, em que as informações obtidas não são necessariamente quantificáveis. As autoras Lüdck e André (1986) exemplificam esta pesquisa por meio de estudos do tipo: etnográfico, naturalístico, participante, estudos de casos e estudos de campo.

Dentre as etapas que compuseram nossa construção metodológica, destacamos: (i) pesquisa via internet em bancos de dados envolvendo dissertações, livros e periódicos da área da Educação Matemática, destacando o tema de nosso estudo; (ii) descrição de memórias e experiências laborais envolvendo conhecimentos matemáticos da/na pesca; (iii) entrevistas semiestruturadas com redeiros e pescadores da comunidade de Provetá, a fim de coletarmos experiências envolvendo conhecimentos matemáticos, e (iv) Coleta de imagens de algumas das práticas laborais da pesca desta comunidade.

\section{Memórias e outras estórias}

Na comunidade de pescadores da Praia de Provetá, sempre que há atividade concernente ao trabalho de colher a rede, o pai ou alguém da família mais experiente estará presente, ajudando ou orientando o jovem aprendiz na hora de puxar os cabos e no embarque do peixe. Com o passar do tempo, espera-se que este aprendiz passe a manejar bem todos os materiais de pesca e esteja preparado para chegar ao patamar mais alto da profissão, que é ser um "proeiro".

Essa posição em uma embarcação de pesca exige conhecimentos específicos, tais como os relacionados à direção dos ventos, e noção de localidade e profundidade. É este o profissional que atuará para que a pesca seja mais rentável.

Entretanto, com o passar dos anos a pesca nessa localidade tem se tornando cada vez mais rarefeita, causando desânimo para os pescadores mais jovens, principalmente quando desejam alcançar melhores ganhos, reconhecimento profissional, e oferecimento de melhores condições para a sua família.

Além dessas problemáticas, ainda convivem com a falta de segurança no trabalho, com problemas relacionados a direitos trabalhistas, e com a vulnerabilidades em relação aos "travessadores"de pesca. O conjunto destes problemas têm causado grande abandono da profissão na região, mesmo após um bom tempo de dedicação ao seu treino.

Há décadas atrás, um numeroso grupo de mulheres faziam parte do trabalho de remendo de redes de pesca de traineira. Mas, destas, muitas já faleceram, ou estão em idade bem avançada, sem possibilidade de exercerem esta função. Infelizmente, a maioria de- 
las não chegou a passar essas experiências laborais para seus filhos. Dentre os grandes motivos para isso ter acontecido, destacamos a inovação empregada na fabricação das redes e a ideia impregnada posteriormente de que este serviço seria coisa somente para os homens fazerem.

Relatos colhidos nos indicaram que, tempos atrás, as redes eram de material de algodão e tinham que ser enxugadas de três em três dias na praia em varais. Pelo fato de serem produzidas originalmente na cor branca, eram tingidas com uma tinta extraída de uma arvore chamada Cobi conhecida no litoral como Pau de cigarra.

\footnotetext{
Quando eu era criança meu pai foi junto com mais dois amigos dele foram buscar um barco em Santos, e quando chegou foi uma festança. Eu e meus irmãos íamos lá para conhecer o barco e atrás uma raça de crianças. O barco estava perto da praia e tiraram a rede do barco e puxaram na praia. A rede era meia branqueada e tinha que secar no sol para depois colocar ela num barril de bronze com tinta de cobi. A rede braqueada espantava os peixes. É por isso que tinha que colocar essa rede no tingidor que deixava a rede com a cor marrom. (Pescador A. - entrevista realizada em outubro/2015).
}

Importante destacar que a introdução de novas tecnologias na fabricação de redes, ao mesmo tempo que tem colaborado para a diminuição da disseminação de conhecimentos desse povoado, passou a possibilitar que os barcos de traineiras façam viagens mais longas e distantes para buscar mais peixes.

Ao focarmos ainda os tempos de poucas tecnologias, quando a pesca era ainda considerada rudimentar, constatamos a informação de que a navegação era precária, sendo tudo manejado manualmente, inclusive a medição de profundidade. Esta, por sinal, era feita com uma corda na qual tinha um pedaço de sabão era amarrado em uma de suas extremidades. Ao ser puxada esta corda, quando este sabão retornava com areia, os pescadores concluíam que o fundo do mar de onde o barco estava era arenoso, se o sabão voltasse com lama, indicava fundo lamacento, e se retornasse todo amassado, indicava fundo pedregoso. Assim, era identificado o local que se podia pescar ou lançar as redes.

Essa percepção era muito importante, pois para as traineiras o melhor lugar para se lançar as redes eram (e ainda são) em locais arenosos ou em altas profundidades, longe das pedras ou cascalhos instalados nos locais de pouca profundidade. Para os arrastões o melhor local é o lamacento, onde a pesca do camarão costuma ser mais produtiva.

De acordo com moradores da comunidade, esses e outros conhecimentos concernentes às práticas laborais e culturais costumam se perder pela renovação das gerações que, por diversos motivos, se distanciam dos conhecimentos dos idosos. Isso se confirma por investigações feitas, não somente em Provetá, mas também em outras praias da Ilha Grande. Segundo Ferreira, Martom e Silva (2015, p. 229),

Este distanciamento motiva desprezo pelas experiências coletivas do passado. 
Passado que como os velhos perdem a utilidade. E assim, no mundo da utilidade imediata de tudo, facilmente se gera a ausência da compreensão do sentido da memória.

Especialmente a falta de incentivo à prática de remendo e armação de redes de pesca tem trazido preocupações aos pescadores na atualidade, pois os jovens não vêm nisso interesse, e não há qualquer mobilização para que esta cultura permaneça nas mãos dos caiçaras, que, por sinal, estão aos poucos mudando para outras atividades laborais, tais como no trabalho em pousadas, ou nos barcos de frete para turistas. Nesse movimento, a cultura de remendo de redes vai sendo gradualmente apagada.

Importante salientar que a própria pesca vem diminuindo. Há diversas outras comunidades da Ilha Grande nas quais não há mais movimentos de pesca, muito menos de redes de traineiras ou arrasto.

\section{Algumas práticas laborais dos pescadores}

Conforme comentado anteriormente, por desejarem que seus filhos tivessem uma profissão, e, ao mesmo tempo herdassem os conhecimentos relacionados à pesca, os pais incentivavam os jovens a acompanharem as pescas em barcos de traineiras de porte médio (12 a 20 toneladas). Essas embarcações enfrentavam o alto mar em busca de sardinhas, e somente ao final de 20 dias de navegação, ou no período da lua cheia (chamado pelos nativos de "período de claro"), os pescadores retornavam para terra firme.

Para exercer corretamente seu ofício, o jovem pescador necessitava conhecer cada peça que compunha a estrutura do barco, assim como suas funções, tais como: (a) anilha: peça que faz a função de guiar a carregadeira a formar um círculo; (b) carregadeira: peça de corda de nylon que serve para puxar a rede; (c) roldana: peça que serve para guiar a carregadeira para o guincho; (d) retinida: cabo de seda ou nylon que serve para alongar o alcance das anilhas e outras funções como cabo de atracação e outras finalidades; (e) cuba: no final de um cabo dar-se uma volta fazendo um pequeno círculo para não se soltar e continuar sem cortá-lo, para fazer um canto reforçado; (f) varejão: peça de bambu longo para afastar o caico e não deixa encostar na borda para não cortar a rede; (g) caico: barquinho sem motor que é arrastado pelo barco maior; (h) sacador: é o final da rede, um pano reforçado feito de linha $36 \mathrm{~mm}$ para suportar grandes quantidades de peixes.

A cada vez que o barco viaja, um tripulante de convés tem a seu cargo a função de guiar o barco. Além disso, cada marinheiro tem uma função na embarcação, por exemplo: (a) chumbereiro: é o que toma conta do chumbo ao lançar a rede, com o auxílio desta posição a rede é lançada para o mar armada; (b) caiqueiro: é o que toma conta do caico (barquinho sem motor que é arrastado pelo barco maior); (c) gelador: é o que gela o 
peixe para não estragar; (d) cozinheiro: tem a função de fazer o café da manhã, almoço, café da tarde e janta; (e) motorista: cuida do motor do barco e das bombas hidráulicas, ficando atento para que a água salgada não provoque alagamento no porão do barco; (f) o mestre: tem responsabilidade com a navegação. No caso de ser ele também proeiro fica a cargo dos aparelhos como radar, sonar e navegador satélite (quando há na embarcação); (g) proeiro: é a pessoa mais importante da embarcação de traineira (e a posição que olha e faz o cerco para apanhar o peixe) e para chegar a esse conhecimento tem que se tornar pescador profissional. Pela sua experiência e vivência no mar o proeiro conhece os movimentos da maré, a direção do vento, e onde encontrar os cardumes de peixes.

\section{Alguns conhecimentos matemáticos dos pescadores}

A palavra etnomatemática segundo D'Ambrosio(2008) é composta de três raizes: etno (diversos ambientes: o social, o cultural, a natureza, etc.), matema (explicar, entender, ensinar e lidar com), etica (lembra a palavra grega tecné, que se refere às artes, técnicas, maneiras). Portanto, sintetizando essas três raízes, temos etno+matema+tica, ou etomatemática, que, significaria então, o conjunto de artes, técnicas de explicar e de entender, de lidar com o ambiente social, cultural e natural, desenvolvido por distintos grupos culturais.

Segundo Esquincalha (2014), a ideia central do Programa da Etnomatemática é que todas as culturas/ sociedades/classes profissionais, grupos identificáveis de forma mais geral, possuem as suas ciências, ou melhor, as suas etnociências.

No intuito de exemplificarmos conhecimentos matemáticos próprios de determinadas culturas, destacamos a que é um dos focos do presente estudo: a de remendo de redes de pesca de traineiras, que se estende às redes de pesca (de arrasto de camarão). Essas redes possuem desenhos geométricos diferentes das comumente utilizadas na pesca, pois são triangulares e circulares, para que os pescadores possam coletar espécies diferentes de peixes ou crustáceos.

Consideramos esta percepção da necessidade de escolha do modelo geométrico como um conhecimento etnomatemático desses profissionais. Entretanto, esses conhecimentos têm caído em desuso, grande parte pelo fato de que esta profissão de redeiro ainda não é legalizada, e não há incentivos públicos nem aparatos tecnológicos para sua substituição, pois se trata de um manejo artesanal e de conhecimento quase sempre passado de pai para filho. Esquincalha (2014, p. 3), destaca que:

A etnociência atua num contexto multicultural, tentando entender os processos de geração e transmissão de conhecimentos, no fazer ciências de cada grupo identificável, com propósito de utilizar esses conhecimentos maternos 
para benefício do próprio grupo, na manutenção de seus valores e práticas culturais/sociais/religioso-profissionais, e de outros grupos, possibilitando uma maior interação entre os mesmos, de forma com que possam coexistir harmoniosamente, sem que haja um processo de aculturação mutua.

A etnomatemática tem sido praticada por diversas culturas com o propósito de manterem vivos seus conhecimentos matemáticos, os quais de forma organizada são transmitidos às novas gerações. Segundo D' Ambrosio (2008), naturalmente, em todas as culturas e em todos os tempos, o conhecimento que é gerado pela necessidade de uma resposta a problemas e situações distintas está subordinado a um contexto natural, social e cultural.

A pesquisa no Programa Etnomatemática recorre a muitos métodos da etnografia, etnologia e antropologia, envolve relatos de experiência, estudos de campo, entrevistas, etc. Tudo pela necessidade de identificar o conhecimento matemático desenvolvido e utilizado pelas/nas comunidades e, em seguida sistematizar este conhecimento.

A utilização de conhecimentos matemáticos na pesca da comunidade selecionada para nosso estudo começa desde a preparação para a saída da embarcação do porto, até o seu retorno, quando o pescador acerta as contas com o proprietário da embarcação e a partilha é feita entre a tripulação. Na saída da embarcação para o início da pescaria, por exemplo, o chumbereiro, que é o responsável por contar cada anilha, faz uma conferência para verificar eventuais faltas do material. Geralmente as redes têm entre 40 a 120 anilhas, e esta contagem permite uma noção de metragem no momento em que for realizando o cerco do cardume de peixes.

$\mathrm{O}$ pescador conta por braças (distância de uma palma da mão à outra) a primeira anilha. Esta marca o início da rede. A distância desta até a próxima anilha será sempre de 12 braças de comprimento, a partir desta conta 10 braças de altura. Com 10 braças de distância chega até a outra anilha, da qual sai outra anilha com 8 braças de altura. Em seguida conta 8 braças de distância, da qual sai outra anilha com 6 braças de altura. E assim por diante, da qual podemos destacar a sequência: 12 (distância) e 10 (altura), 10 (distância) e 8 (altura), 8 (distância) e 6 (altura), 6 (distância) e 4 (altura), 4 (distância) e 2 (altura), 4 (distância) e 1 (altura) até o meio da rede. A partir deste ponto recomeça a contagem, mas desta vez do 1 ao 12 .

Na hora da pescaria propriamente dita, quando a rede é lançada ao mar, o chumbereiro tem que contar as anilhas gritando "1, 2, 3,..", para que possam organizadamente fazerem o cerco. Se esta contagem for atropelada, ou se houver qualquer tipo de erro, correse o risco de perder toda a pescaria. Além desses e outros diversos tipos de exemplos que poderíamos aqui elencar, que envolvem conhecimentos matemáticos nas atividades laborais da pesca, destacamos, em especial, o momento de finalização da pescaria, que é a partilha dos lucros. Ela nos é apresentada nas palavras de um pescador entrevistado. 
Supondo que a embarcação faça, durante um período de pesca, $\mathrm{R} \$ 500.000,00$ e que as despesas de combustível, alimentação, e tal... tenham contabilizado $\mathrm{R} \$ 150.000,00$. O primeiro cálculo a ser feito é descontar dez por cento do valor do total que será destinado ao proprietário do barco, e o total das despesas. Desta forma teríamos $\mathrm{R} \$ 300.000,00$. Este novo valor será dividido ao meio. Neste caso, em duas partes iguais de $\mathrm{R} \$ 150.000,00$. Apenas uma delas destinada aos tripulantes da embarcação. A partir daí o valor de $\mathrm{R} \$ 150.000,00$ será dividido em 30 partes iguais. Será de $\mathrm{R} \$$ 5.000,00 cada. Cada um dos tripulantes receberá sua parte de acordo com a função que exerce. O proeiro, que é a mais importante, ganha 10 partes, ou seja, $\mathrm{R} \$ 50.000,00$. O contra mestre, 3 partes, $\mathrm{R} \$ 15.000,00$. O motorista 3 partes, $\mathrm{R} \$ 15.000,00$. O cozinheiro $2 \frac{1}{2}, \mathrm{R} \$ 12.500,00$. O caiquiero $1.1 / 4$ de partes, $\mathrm{R} \$ 6.750,00$. E assim sucessivamente, até chegar às trinta partes. (Pescador G. - entrevista realizada

Interessante destacar que, no passadodo, todos esses cálculos, por sinal bastante longos e complexos, eram realizados por mestres de barcos de pesca que não tinha nenhum conhecimento formalizado de matemática. Toda partilha era feita por pontinhos ou palitos de fósforos que serviram para contabilizar as partes que cabiam a cada trabalhador. Depois de fazerem os cálculos, conferiam quantos palitos tinham cada tripulante, e este recebia de acordo com essa quantidade.

Desde os primórdios, os pescadores já executavam essa tarefa de partilhar as vendas dos peixes, e isso era dividido em partes que variavam de uma parte e meia $\left(1 \frac{1}{2}\right)$ a uma parte e um quarto $\left(1 \frac{1}{4}\right)$. Para realizarem estes, e outros cálculos, usavam, além de palitos, os dedos das mãos. Eles também conheciam muito sobre formas de medida das redes e as calculavam quase sempre usando braças, tal como ocorria quando queriam calcular o tamanho de um pano de rede (normalmente mede 100 metros).

Por exemplo, se um pano de rede tinha 100 metros de comprimento e 10 metros de altura, em braças ela teria 60 braças, de comprimento e 6 braças de altura. Eles calculavam na corda principal (tralha), isto é, entralhado quarenta e 5 braças pela cortiça e 48 pelo chumbo.

Se uma rede tinha quatrocentas braças na tralha (ou entralhado), teria seiscentos metros de comprimento. Isso se dava por causa do entralho que encolhe as malhas. Esses cálculos eram necessários, pois poderia comprometer toda armação da rede de traineira, se caso um pano estivesse maior que o outro. Este material ficaria desbalanceado e assim não teria um bom funcionamento.

Destacamos que um pano de rede vem de fábrica com medida de 100 metros. Para se formar uma rede são necessários de 8 a 9 panos de cem metros, e, ao confeccioná-la encaixa-se uma rede com outra, e os 100 metros encolhem, ficando com 45 braças na cortiça e 48 braças pelo chumbo, tendo o resto de 5 mtros, que fica embebido na rede. Fazendo o cálculo: 100 - 45/50 restos de 5. Cada 100 metros medidos em braças são 60 braças. No total uma rede com 9 panos fica com 9 x 45= 405 braças pela cortiça e 9 x 50 $=450$ braças pelo chumbo. 


\title{
5 Conversas com pescadores
}

As diversas conversas/entrevistas que realizamos para a coleta de informações que compuseram este estudo nos levaram a destacar dois informantes chave que apresentaremos neste último tópico do artigo. Apresentamos inicialmente o Sr. Ferreira, um pescador profissional de 70 anos de idade e ainda em atividades na pesca, residente na Praia de Provetá.

Uma das primeiras perguntas que fizemos foi a respeito de sua escolaridade. Obtivemos como resposta a informação de que cursou apenas até a segunda série do antigo primário, e abandonou a escola com 13 anos de idade. A partir daí passou a se dedicar à pesca. Em seguida, emendou estas informações com outras relacionadas às medidas da rede de pesca, que teriam por finalidade adequar as panagens (panos de rede), e outros materiais, para fazer uma boa pescaria.

\footnotetext{
Quando se arma uma rede, tem que se colocar as anilhas. A primeira anilha vai do chumbão, medido 12 braças pelo chumbo. Ai a primeira anilha, que tem 10 braças, aí depois diminui duas braças. Aí vem 10 braças de chumbo, e a segunda anilha, 8 braças de cabo. Depois diminui para 8 no chumbo, e 6 de cabo. Assim até chegar as de 6 pelo chumbo e 1 uma braça de cabo. Pelo tanto de anilhas é que se sabe o tamanho da rede. Exemplo, se multiplicar as anilhas se sabe o tamanho da rede. 80 anilhas vezes 6 braças é igual a 480, incluindo 6 mais 6 igual a 12 mais 10 menos 2 mais 8 menos 2 menos 2 igual a 24 mais 480 igual a 504 braças. A rede não se mede pela cortiça, mas pelo chumbo. Porque quando a cortiça acaba, o chumbo continua saindo. Eu remendo rede desde criança.
}

Ao ser questionado a respeito das divisões da renda do pescado, e como era feito essa partilha, respondeu:

\begin{abstract}
A conta hoje em dia não é mas feita pelo mestre, e sim pelo próprio dono. Exemplo, se o barco fez 300 mil se tira dez por cento deste valor, tira mais 50 de despesas. Aí tem 80 menos 300, igual a 220. Ele divide em 2 partes. Aí fica 220 dividido por 2 igual a 110 para ele, e 110 para a tripulação. Se o barco tem 30 partes aí divide 110 dividido por 30, igual a 3. Dá 66 para cada tripulante.
\end{abstract}

Os conhecimentos apresentados nesta entrevista mostram o quanto a etnomatemática está presente nesta cultura caiçara, mesmo que eles não percebam. Os cálculos e as formas de lidar com a complexidades matemáticas resultam do trabalho de subsistência da comunidade, que sobreviveu durante um bom tempo da pesca.

Há situações de luta para manter essas tradições vivas como instrumentos de apoio para lidar com outras culturas. Segundo D'Ambrosio (2008, p.12), "ao se trabalhar com outras comunidades há um esforço para se utilizar os instrumentos intelectuais e materiais para finalidades de trabalhar com a cultura dominante". 
Os pescadores redeiros da Praia de Provetá, como o Sr Ferreira, comentam com facilidade sobre o seu manejo com os materiais de rede de pesca. Nesta entrevista percebemos o quanto a cultura matemática está intrínseca em suas atividades laborais do mar, tais como nas contagens diversas, nas medições e na utilização de diferentes formas angulares utilizadas nas redes para realização do trabalho de captura de diferentes tipos e tamanhos de peixes.

Em seguida, abrimos espaço para a entrevista realizada com o Sr. Martins, 62 de idade e 50 anos de profissão de pescador profissional da Praia de Provetá. Atualmente é proprietário de um barco de pesca de sardinha de 30 toneladas. Em relação às formas de remendo de rede de traineiras, o entrevistado nos deu as seguintes informações:

\begin{abstract}
As redes de traineiras são levadas para a praia ou cais para reparo. Lá a rede é esticada para se ter uma noção do quanto de serviço se vai fazer. A rede é medida, porque quando vai para a água com a força da maré e ventos, ela estica e perde o seu aumento, que, feito por medição de braças, no chumbo tem que ter no mínimo 25 a 30 braças de aumento. Essa medição é feita na hora em que vai embarcar a rede no barco. A junta cortiça, com o chumbo, numa medição paralela. No final a cortiça acaba e o chumbo continua até as 25 ou 30 braças.
\end{abstract}

Ao ser questionado sobre a profissão de redeiro, respondeu:

\begin{abstract}
É uma profissão pouco procurada, por não haver pessoas interessadas. Remendadores temos muito poucos. São aqueles pescadores antigos que já se aposentaram e estão ali para ganhar uns trocados. Há pescadores novos que também entendem muito de rede e estão começando a trabalhar neste ramo. Costurar rede não é fácil, meu tio era redeiro. Ele trabalhava, e mostrava para os seus companheiros o quanto é de responsabilidade entralhar, perfilhar, e medir uma rede, para que o barco saia do porto e vá para o pesqueiro, e lá encontre o peixe. E para a rede trabalhar bem para se ter uma boa pescaria.
\end{abstract}

De acordo com Sr. Martins, os redeiros não são estimulados a continuarem seus legados, pois, em geral, não é uma profissão que desejam para os seus filhos. Esse manejo de costura de rede depende do bom conhecimento que o pescador tem das malhas de uma traineira e isso é transmitida por informações de outros com mais experiência neste ramo.

Segundo D'Ambrosio (2008, p. 22), a respeito do fazer matemático presente no cotidiano, "a todo instante, os indivíduos estão comparando, classificando, quantificando, medindo, explicando, generalizando, inferindo e, de algum modo, avaliando, usando instrumentos materiais e intelectuais que são próprios de sua cultura".

Destacamos que esta entrevista nos levou a perceber que as formas de trabalhos dos pescadores, tanto no manejo das redes, quanto na captura dos peixes, envolve um entrosamento de pessoas e uma grande quantidade de conhecimentos específicos da profissão. Por isso as comunidades caiçaras tendem a perder seus espaços de atuação, pois estes 
grupos a cada dia perdem mais seus conhecimentos, em especial, pela desvalorização da profissão da pesca, e do remendo de redes, visando outras formas de autossuficiência.

\section{Considerações finais}

Nesta produção abrimos espaço para alguns conhecimentos matemáticos que são utilizados pela comunidade de pescadores da praia de Provetá, em atividades laborais relacionadas à sua profissão. São contagens e medições diversas que são feitas, mesmo por aqueles que são considerados analfabetos, ou analfabetos funcionais, passadas anteriormente de geração para geração, como forma de manutenção e resistência de uma cultura que vivia apenas da pesca.

Constatamos que esse quadro vem gradualmente sendo modificado, e que tais conhecimentos estão se perdendo, por razões diversas, mas especialmente pelo fato do não reconhecimento e valorização adequada da profissão de pescador. Isso tem levado as novas gerações das comunidades de Provetá a buscarem outras profissões, e, até mesmo a abandonarem a própria comunidade.

Consideramos que este nosso estudo contribui para pertinentes discussões relacionadas às questões que envolvem cultura de comunidades, e seus conhecimentos específicos, não apenas de matemática, mas de todas as áreas, que são desenvolvidas como forma de respostas aos seus problemas, e à necessidade de sobrevivência.

\section{Referências}

[1] D’ AMBROSIO, Ubiratan. Etomatemática - elo entre as tradições e a modernidade. $5^{\text {a }}$ edição. Belo Horizonte: Autêntica, 2008.

[2] ESQUINCALHA, A. C. Etnomatemática: um estudo da evolução da ideias. In: VIII Encontro Nacional de Educação Matemática, 2004, Recife. Anais do VIII Encontro Nacional de Educação Matemática, 2004. P. 1-6. Disponível em: «https://docplayer.com.br/18693621-Etnomatematica-um-estudo-daevolucao-das-ideias.html $\gg$. Acesso em: 27 dez. 2019.

[3] FERREIRA, Maria Onete Lopes; MARTON, Silmara Lidia, e SILVA, Dagmar de Mello e. Memórias caiçaras: aproximações preliminares. Cuba: Congresso Universidad, vol IV, n.1, p. 227-239, 2015.

[4] LÜDKE, M.; ANDRÉ, M. E. D. A. Pesquisa em educação: abordagens qualitativas. São Paulo, E.P.U, 198699 p. 
[5] RODRIGUES, William Costa. Metodologia Científica. Editora FAETEC, Paracambi, 2007.

Submetido em jul. 2019

Aceito em dez. 2019 